\title{
MicroRNA-124 mediates the cholinergic anti-inflammatory action through inhibiting the production of pro-inflammatory cytokines
}

\author{
Yang Sun ${ }^{1, *}$, Qi Li $^{1, *}$, Huan Gui ${ }^{1}$, Dong-Ping Xu${ }^{1}$, Yi-Li Yang ${ }^{2}$, Ding-Feng Su ${ }^{1}$, Xia Liu ${ }^{1}$ \\ ${ }^{I}$ Department of Pharmacology, School of Pharmacy, Second Military Medical University, Shanghai 200433, China, ${ }^{2}$ Cancer and \\ Developmental Biology Laboratory, National Cancer Institute, National Institutes of Health, Frederick, MD 21702, USA
}

The vagus nerve can control inflammatory response through a 'cholinergic anti-inflammatory pathway', which is mediated by the $\alpha 7$-nicotinic acetylcholine receptor $(\alpha 7 \mathrm{nAChR})$ on macrophages. However, the intracellular mechanisms that link $\alpha 7 \mathrm{nAChR}$ activation and pro-inflammatory cytokine production remain not well understood. In this study, we found that miR-124 is upregulated by cholinergic agonists in LPS-exposed cells and mice. Utilizing miR-124 mimic and siRNA knockdown, we demonstrated that miR-124 is a critical mediator for the cholinergic anti-inflammatory action. Furthermore, our data indicated that miR-124 modulates LPS-induced cytokine production by targeting signal transducer and activator of transcription 3 (STAT3) to decrease IL-6 production and TNF- $\alpha$ converting enzyme (TACE) to reduce TNF- $\alpha$ release. These results also indicate that miR-124 is a potential therapeutic target for the treatment of inflammatory diseases.

Keywords: microRNA-124; cholinergic anti-inflammatory action; $\alpha 7 \mathrm{nAChR}$; macrophages; septic shock; STAT3; TACE Cell Research (2013) 23:1270-1283. doi:10.1038/cr.2013.116; published online 27 August 2013

\section{Introduction}

During infections and injuries, the innate immune system is activated to release pro-inflammatory cytokines, such as IL-6 and TNF- $\alpha$. They initiate the development of inflammatory responses that play an important role in controlling infection and promoting tissue repair [1]. However, the magnitude of the cytokine production and inflammation response is critical. An excessive response could be more harmful than the original insult, leading to the development of a variety of inflammatory and autoimmune diseases. Many studies have demonstrated that a number of humoral factors, such as glucocorticoids, act as potent modulators of the inflammatory response dur-

\footnotetext{
*These two authors contributed equally to this work. Correspondence: Xia Liu ${ }^{\mathrm{a}}$, Ding-Feng Su ${ }^{\mathrm{b}}$, Yi-Li Yang

${ }^{a}$ Tel: (+86)-21-81871270; Fax: (+86)-21-65493951

âE-mail: lxflying@aliyun.com

bE-mail: dfsu2008@gmail.com

'E-mail: yiliyang@mail.nih.gov

Received 6 April 2013; revised 4 July 2013; accepted 15 July 2013; published online 27 August 2013
}

ing various stress conditions $[2,3]$. Recent investigations also indicated that the vagus nerve of the autonomic nerve system participates in the regulation of the inflammatory response $[4,5]$. It has been shown that, when animals were challenged by infection or injury, the action potentials originating from the vagus nerve regulate $\mathrm{T}$ cells, which produce acetylcholine $(\mathrm{ACh})$ that in turn acts on tissue macrophages and inhibits the production of pro-inflammatory cytokines [6, 7]. Interestingly, stimulation of the vagus nerve or nicotine, an agonist of the nicotinic ACh receptor, can attenuate the production of the pro-inflammatory cytokines and improve the survival of animals under various experimental conditions, including sepsis, haemorrhagic shock, and ischaemia-reperfusion injuries [4, 8-10]. Therefore, the cholinergic anti-inflammatory pathway is not only an important physiological mechanism, but also a promising target for therapeutic intervention.

The transmembrane receptors for ACh (AChR) are classified according to their relative sensitivities to nicotine and muscarine. While the muscarinic AChRs (mAChRs) are G-protein-coupled receptors, the nicotinic AChRs (nAChRs) are cation ion channels formed by 
five subunits. A significant number of $\mathrm{nAChR}$ subunits have been identified, including ten $\alpha(\alpha 1-10)$, four $\beta$ ( $\beta 1-4)$, and one each of $\gamma, \delta$ and $\varepsilon$. The $\alpha 7 \mathrm{nAChR}$ is one of the most abundant nAChRs in the brain and is also expressed in many non-neuronal cells, including epithelial, endothelial, immunological, and some cancer cells [11]. Intriguingly, $\alpha 7 \mathrm{nAChR}$ is more permeable to $\mathrm{Ca}^{2+}$ than other nAChRs and can utilize multiple amplification mechanisms to raise the intracellular calcium levels and activate multiple $\mathrm{Ca}^{2+}$-dependent kinases. One of the transcription factors activated is cAMP response element binding protein (CREB) $[12,13]$. It has been shown that $\alpha 7 \mathrm{nAChR}$ is essential for the cholinergic anti-inflammatory action, as stimulation of the vagus nerve could not inhibit TNF- $\alpha$ synthesis in $\alpha 7 \mathrm{nAChR}$-deficient mice $[5,14]$. However, the intracellular mechanisms that link $\alpha 7$ nAChR activation and pro-inflammatory cytokine production remain largely unclear.

MicroRNAs (miRNAs) are non-coding transcripts of 18-25 nucleotides that are processed from large primary transcripts, which are commonly transcribed by RNA polymerase II $[15,16]$. After initial processing by RNase Drosha in the nucleus, the pre-miRNA is transported to the cytoplasm where the miRNA hairpin is cleaved by endoribonuclease Dicer, forming a miRNA duplex. One of the RNA strands then binds to the RNAinducing silencing complex and guides the complex to the 3 '-untranslated regions (UTRs) of target mRNAs, leading to their degradation or inhibition of their translation. It has been estimated that there are approximately 5 000-10 000 miRNAs in mammalian cells, which control the expression of more than $60 \%$ of the protein-coding genes. Increasing evidence indicates that most, if not all, physiological and pathological processes, including inflammatory responses, are modulated by miRNAs at multiple levels. Interestingly, miRNAs usually affect target gene expression in the range of 1.2-4.0 folds, suggesting that, rather than functioning as on-off switches for genes, they modulate and fine-tune the expression of target genes [17]. It is also worth noting that, although it is generally believed that the changes of miRNA expression are controlled at the level of transcription, proteins that are involved in generating miRNA from its precursor can also exert their influences [18]. We found that miR124 is highly induced by $\alpha 7 \mathrm{nAChR}$ activation. miR-124 mediates the cholinergic anti-inflammatory action by inhibiting LPS-induced production of pro-inflammatory cytokines, and a miR-124 agomir could effectively protect mice from septic shock. Additionally, both $\alpha 7 \mathrm{nAChR}$ agonist and miR-124 mimic inhibit LPS-induced IL-6 mRNA production, but not that of TNF- $\alpha$. This is consistent with a previous report that ACh decreased IL-1-in- duced IL-6 production in fibroblast-like synoviocytes by reducing the IL-6 mRNA level [19]. Our further analysis indicated that miR-124 targets STAT3, which is required for LPS-induced IL-6 transcription, as well as TACE, which is required for the maturation of TNF- $\alpha$ protein. These results reveal novel mechanisms of the cholinergic anti-inflammatory action and provide valuable targets and strategies for therapeutic intervention of inflammatory diseases.

\section{Results}

$T N F-\alpha$ and IL-6 expression are inhibited by $\alpha 7 n A C h R$ activation at post-transcriptional and transcriptional level, respectively

To understand the mechanism responsible for the cholinergic anti-inflammatory action, we examined the effect of nicotine, an $\alpha 7 \mathrm{nAChR}$ agonist, on cytokine production in LPS-treated macrophage cell line RAW264.7. Among the pro-inflammatory cytokines, IL- $1 \beta$ was undetectable in the supernatant and IL-10 level was not affected by nicotine as previously reported [4]. Interestingly, although nicotine decreased TNF- $\alpha$ and IL-6 production in a dose-dependent manner, it only reduced the mRNA level of IL-6 (Figure 1A and 1B). Similar results were also obtained using primary peritoneal macrophages from mice (Figure 1C and 1D). These findings prompted us to ask whether miRNAs, which could affect both the stability and translation of mRNA, are involved in the cholinergic anti-inflammatory action. When Dicer, the key enzyme in miRNA maturation, was knocked down, the inhibitory effects of nicotine on pro-inflammatory cytokine production were significantly attenuated. The inhibition ratio of nicotine on LPS-induced IL-6 production was reduced from $77.3 \%$ to $26.1 \%$. The inhibition of nicotine on TNF- $\alpha$ production was reduced modestly by knockdown of Dicer ( $85 \%$ to $76 \%$ ) (Figure 1E).

\section{miR-124 is induced by $\alpha 7 n A C h R$ activation}

A number of miRNAs have been found to regulate inflammation and immunity. miR-155 and miR-125b are involved in the regulation of TNF- $\alpha$ production; miR$146 \mathrm{a} / \mathrm{b}$ was proposed to control Toll-like receptor (TLR) signaling; miR-181a modulates the production of CD4 and CD8 double-positive T cells; miR-124 was found to inhibit the activation of microglial cells; and miR-223 negatively regulates the proliferation and differentiation of neutrophils [20-23]. To identify the potential miRNAs involved in the cholinergic anti-inflammatory action, expression of these miRNAs was examined by quantitative PCR. Interestingly, while the levels of miR-125b, miR125b-1, miR-146a, miR-146b, miR-155, miR-181a, miR- 
A

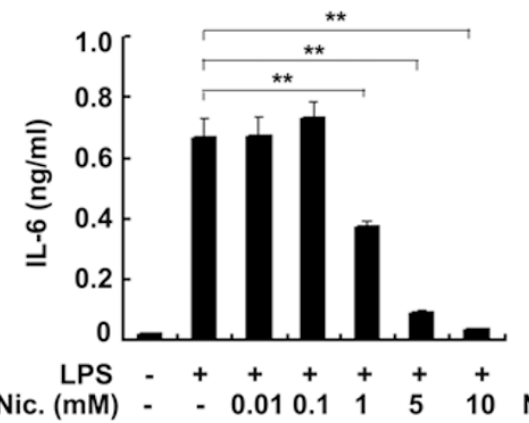

Nic. (mM) - $\quad-\quad 0.010 .1 \quad 1 \quad 5 \quad 10$

C
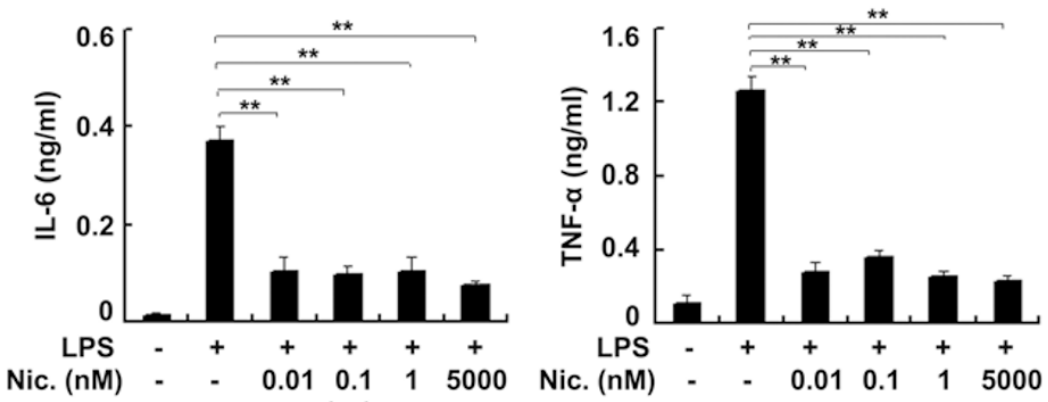

B
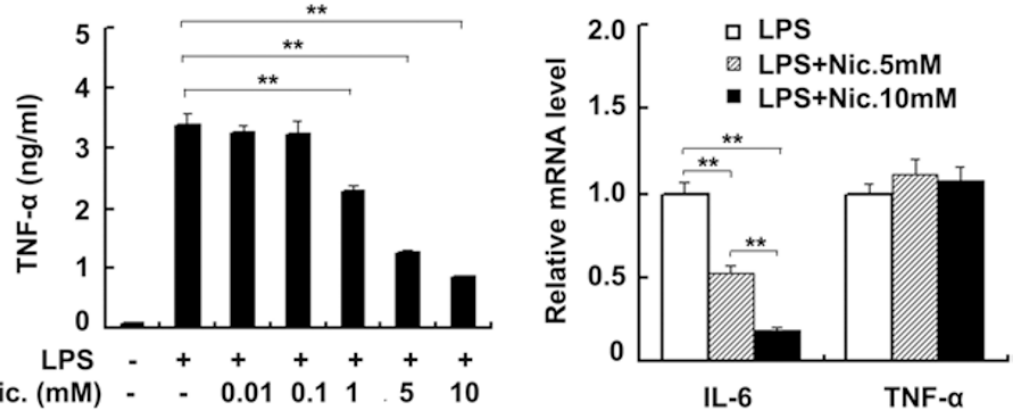

D

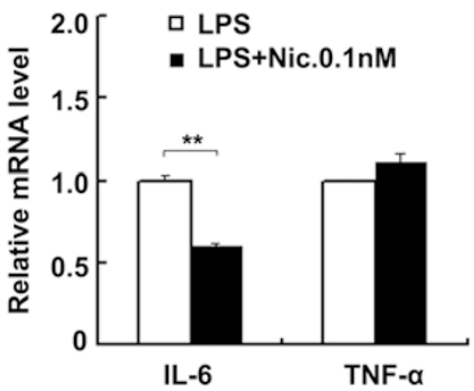

E
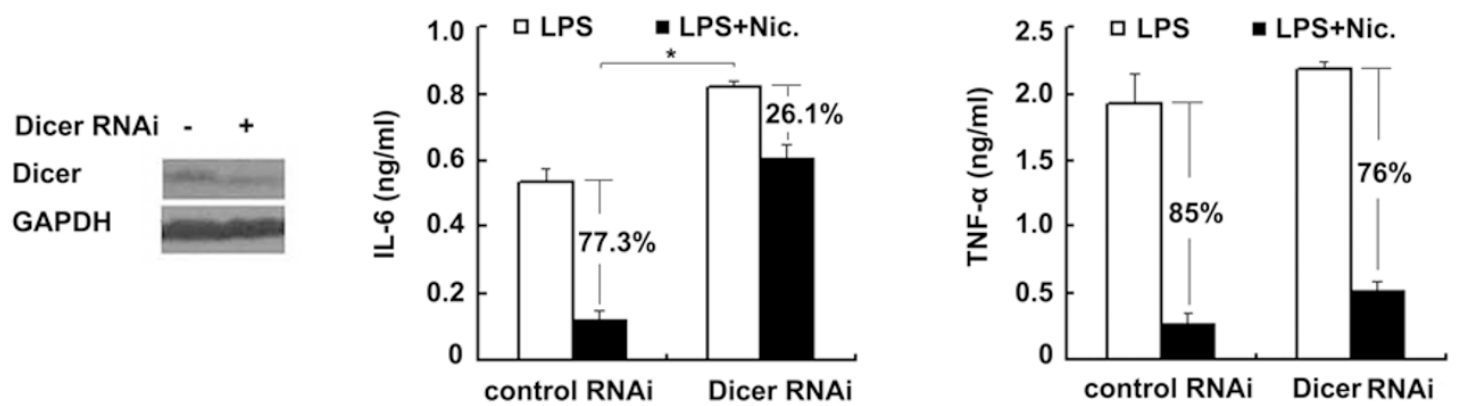

Figure 1 The inhibitory actions of nicotine on LPS-induced IL-6 and TNF- $\alpha$ productions are mechanistically different. (A) ELISA and (B) q-PCR detection of IL-6 and TNF- $\alpha$ in RAW264.7 macrophages incubated with vehicle or the indicated amounts of nicotine for $10 \mathrm{~min}$ and then stimulated with vehicle or $100 \mathrm{ng} / \mathrm{ml}$ LPS for $9 \mathrm{~h}$. (C) ELISA detection of IL- 6 and TNF- $\alpha$ in the supernatant of peritoneal macrophages incubated with vehicle or the indicated concentrations of nicotine for 10 min and stimulated with vehicle or $1 \mathrm{ng} / \mathrm{ml}$ LPS for $9 \mathrm{~h}$. (D) q-PCR detection of IL-6 and TNF- $\alpha$ mRNAs in peritoneal macrophages treated with $1 \mathrm{ng} / \mathrm{ml}$ LPS in the presence or absence of $0.1 \mathrm{nM}$ nicotine. (E) RAW264.7 cells were transfected with control siRNA or siRNA against Dicer for $48 \mathrm{~h}$ (Dicer protein was examined with immunoblotting, left panel, representative of three independent experiments), and stimulated with LPS in the presence or absence of $5 \mathrm{mM}$ nicotine. IL- 6 and TNF- $\alpha$ were measured by ELISA. The percentages were calculated using LPS alone as $100 \%$. Data represent mean $\pm \operatorname{SD}(n=3) .{ }^{*} P<0.05,{ }^{* *} P<0.01$ by Student's $t$-test.

$181 \mathrm{c}$ and miR-223 were not affected by nicotine treatment, miR-124 increased by nearly 4 -fold in the presence of nicotine (Figure 2A). This effect was also observed in mice peritoneal macrophages (Figure $2 \mathrm{~B}$ ). As shown in Figure 2C, expression of miR-124 increased $3 \mathrm{~h}$ after exposure to LPS and nicotine, and reached the highest level at $9 \mathrm{~h}$ post-treatment. Meanwhile, the inhibition of IL-6 and TNF- $\alpha$ secretions also became significant $9 \mathrm{~h}$ after nicotine treatment, suggesting that miR-124 could mediate the cholinergic anti-inflammatory action.

Both genetic and pharmacological approaches were utilized to determine whether miR-124 upregulation is 
A

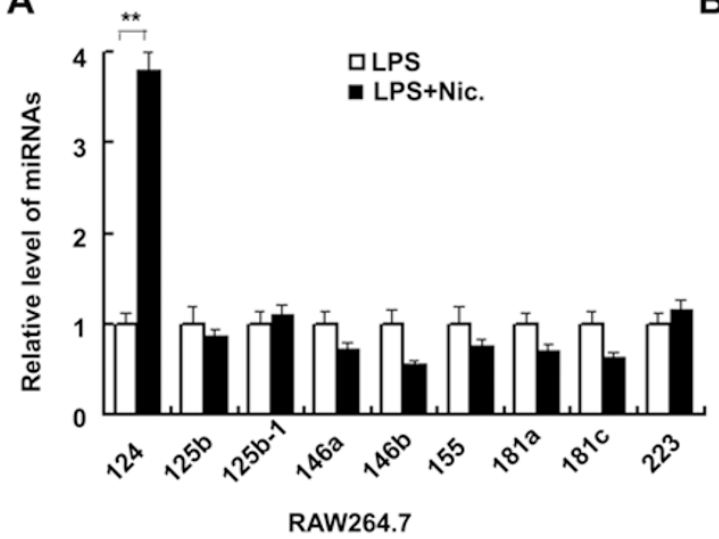

D

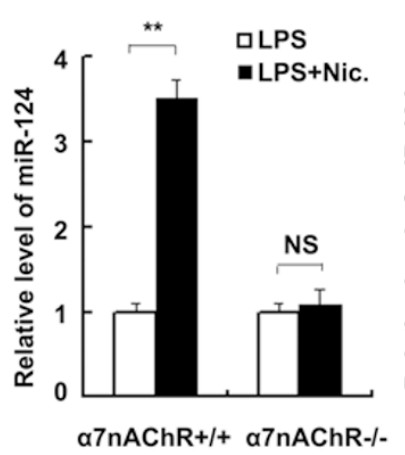

E

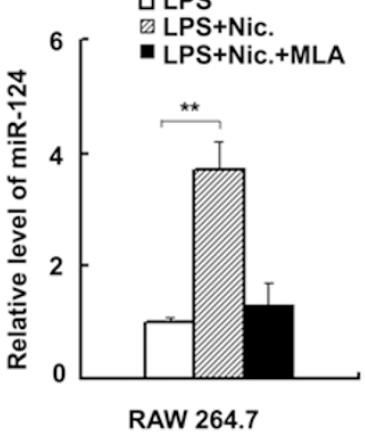

B

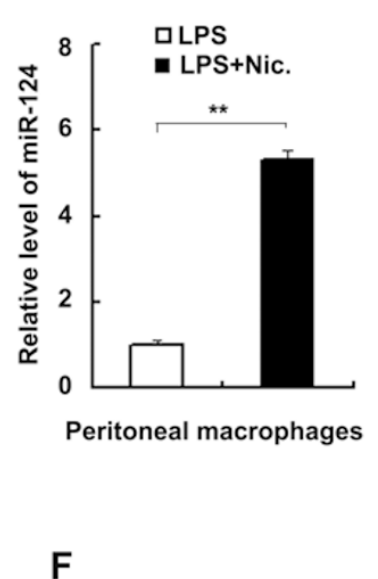

C
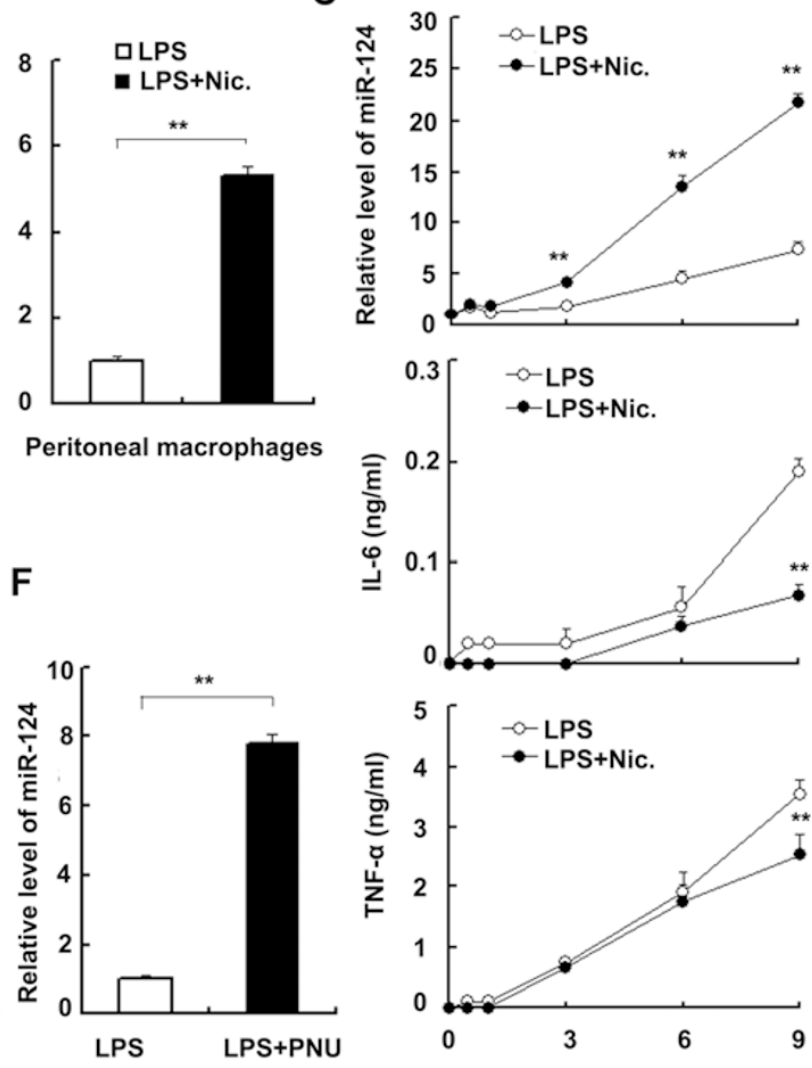

LPS

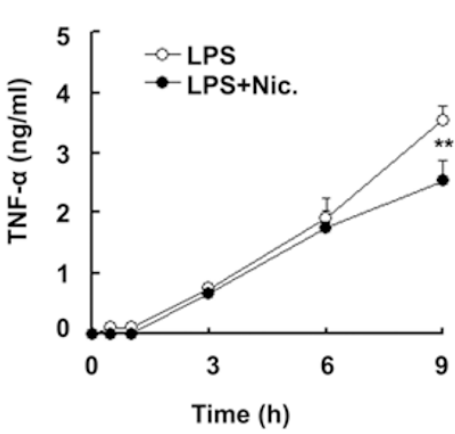

Figure 2 a7nAChR activation upregulates miR-124. (A) q-PCR of miRNAs in RAW264.7 cells stimulated with $100 \mathrm{ng} / \mathrm{ml}$ LPS in the absence or presence of $5 \mathrm{mM}$ nicotine for $9 \mathrm{~h}$. (B) q-PCR of miR-124 in mice peritoneal macrophages stimulated with $1 \mathrm{ng} / \mathrm{ml}$ LPS in the absence or presence of $0.1 \mathrm{nM}$ nicotine for $9 \mathrm{~h}$. (C) Time courses of miR-124 induction in RAW264.7 cells stimulated with $100 \mathrm{ng} / \mathrm{ml}$ LPS with or without $5 \mathrm{mM}$ nicotine. IL- 6 and TNF- $\alpha$ productions in the supernatant were determined by ELISA. (D) q-PCR of miR-124 in peritoneal macrophages of $\alpha 7 \mathrm{nAChR}{ }^{+/+}$or $\alpha 7 \mathrm{nAChR}{ }^{-/-}$mice treated with $1 \mathrm{ng} / \mathrm{ml} \mathrm{LPS}$ with or without $0.1 \mathrm{nM}$ nicotine for $9 \mathrm{~h}$. (E) q-PCR of miR-124 in RAW264.7 cells pre-incubated with vehicle, $5 \mathrm{mM}$ nicotine, $5 \mathrm{mM}$ nicotine in combination with $10 \mu \mathrm{M}$ MLA and then stimulated with $100 \mathrm{ng} / \mathrm{ml}$ LPS for $9 \mathrm{~h}$. (F) q-PCR of miR-124 in RAW264.7 cells pre-incubated with $5 \mu \mathrm{M}$ PNU for $10 \mathrm{~min}$ and then stimulated with vehicle or $100 \mathrm{ng} / \mathrm{ml}$ LPS for $9 \mathrm{~h}$. Data represent mean $\pm \mathrm{SD}(n=3)$. NS, not significant $(P>0.05) ;{ }^{* *} P<0.01$ by Student's $t$-test.

dependent on $\alpha 7 \mathrm{nAChR}$ activation. Nicotine failed to suppress the production of LPS-induced pro-inflammatory cytokines in peritoneal macrophages from $\alpha 7 \mathrm{nAChR}$ deficient mice as reported (Supplementary information, Figure S1A). Neither could it upregulate the level of miR-124 in these cells (Figure 2D). Similarly, MLA, a selective $\alpha 7 \mathrm{nAChR}$ antagonist, abolished the upregulation of miR-124 expression by nicotine (Figure 2E and Supplementary information, Figure S1B) in RAW264.7 cells. Furthermore, the $\alpha 7 \mathrm{nAChR}$-selective agonist PNU inhibited IL-6 production in RAW264.7 cells in a dosedependent manner (Supplementary information, Figure $\mathrm{S} 1 \mathrm{C})$, and it increased miR-124 expression more effectively (by nearly 8 -fold) than nicotine (by approximately 4-fold) when $5 \mu \mathrm{M}$ drug was used (Figure 2F). These results indicate that upregulation of miR-124 by nicotine requires $\alpha 7 \mathrm{nAChR}$.

miR-124 mediates the differential effects of $\alpha 7 n A C h R$ activation on the expression of TNF- $\alpha$ and IL-6 in macrophages

To directly assess the effect of miR-124 on the production of pro-inflammatory cytokines, a miR-124 mimic was transfected into RAW264.7 cells. As shown in Figure 3A, expression of the miR-124 mimic (Supplementary information, Figure S2A) resulted in a significant reduction in LPS-induced IL- 6 and TNF- $\alpha$ production, but had no effect on IL-10 production (data not shown). Interestingly, the miR-124 mimic decreased the level of IL-6 mRNA in a dose-dependent manner, but not that 
of TNF- $\alpha$ (Figure 3B), suggesting that it does not directly block signaling through TLR4. To further evaluate the role of miR-124 in the anti-inflammatory action of nicotine, LPS-induced miR-124 was knocked down in the RAW264.7 cells. As shown in Figure 3C, miR-124 knockdown (Supplementary information, Figure S2B) significantly attenuated the inhibitory effect of nicotine on LPS-induced IL- 6 and TNF- $\alpha$ production. Furthermore, miR-124 knockdown abolished the inhibitory effect of nicotine on the level of IL-6 mRNA, but had no influence on the level of TNF- $\alpha$ mRNA (Figure 3D). These data demonstrate that miR-124 is required and sufficient for the cholinergic anti-inflammatory action under these experimental conditions.

miR-124 is essential for the anti-inflammatory effect of the cholinergic pathway in LPS-induced septic mice

The critical role of miR-124 in cultured cells led us to speculate whether it is involved in the anti-inflammatory action of nicotine in vivo. Among the tissues and organs examined in normal mice, brain and colon express relatively high levels of miR-124 (Figure 4A). After injection of LPS, expression of miR-124 was significantly increased in the spleen, brain and colon (by 10-, 3 - and 2-fold, respectively; Figure 4A). In the presence of nicotine $(2 \mathrm{mg} / \mathrm{kg}$ body weight), which effectively decreased LPS-induced serum IL- 6 and TNF- $\alpha$ levels (Supplementary information, Figure S3A), the miR-124 level was further increased by 2 -fold in the spleen and brain (Figure 4A). The administration of the $\alpha 7 \mathrm{nAChR}$ selective agonist PNU inhibited pro-inflammatory cytokine production (Supplementary information, Figure S3B) and increased the level of miR-124 in the spleen by 6.1 -fold (Figure 4B). Interestingly, the serum miR124 level was also elevated by LPS injection and was further increased with the addition of nicotine (data not shown). These data indicate that the spleen is one of the major miR-124-producing peripheral organs in response to LPS and nicotine, which is consistent with the finding that the spleen is the main target of the cholinergic antiinflammatory pathway $[24,25]$.

To determine whether miR-124 plays an essential
A
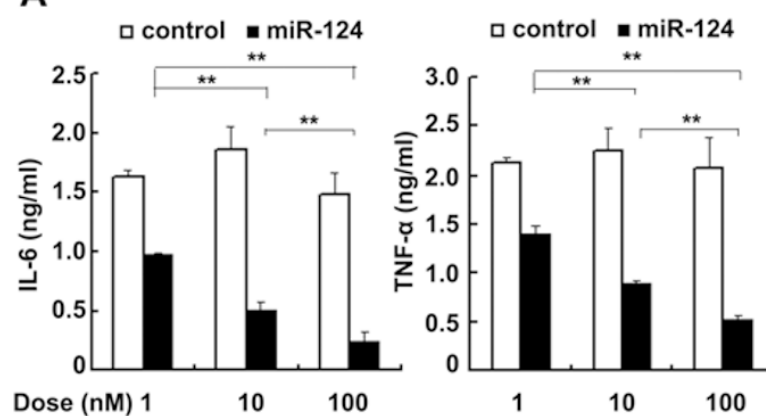

C
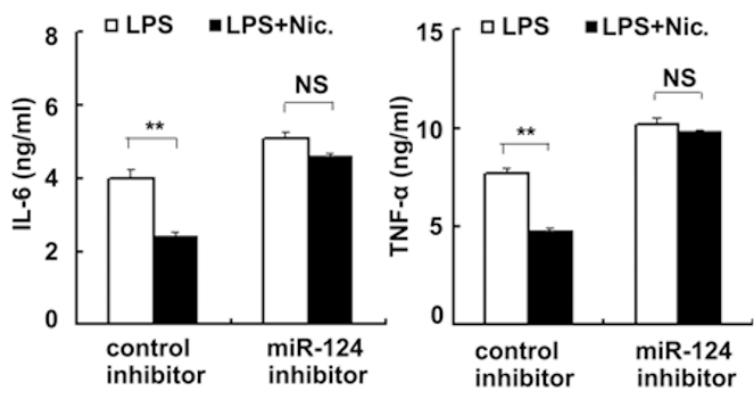

B

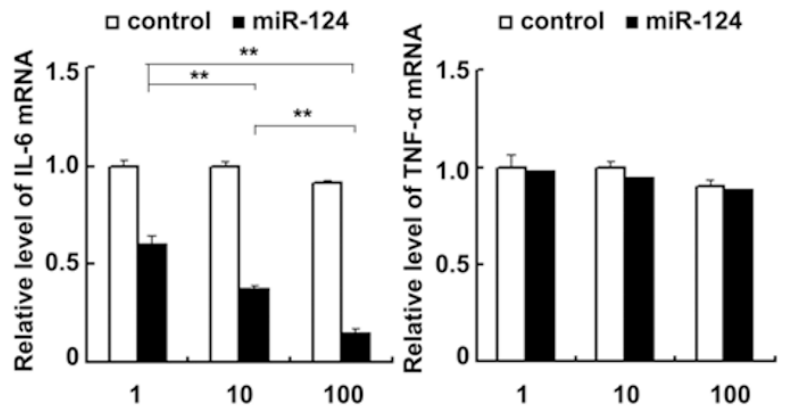

D
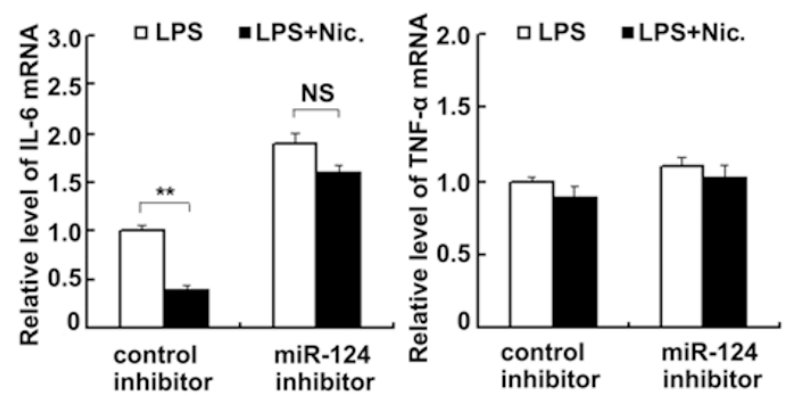

Figure 3 miR-124 mediates the cholinergic inhibitory actions on IL-6 and TNF- $\alpha$ production. For A and B, RAW264.7 cells were transfected with the indicated amounts of miR-124 mimic or negative control for $36 \mathrm{~h}$ and then stimulated with $100 \mathrm{ng} / \mathrm{ml} \mathrm{LPS}$ for 9 h. (A) IL-6 (left panel) and TNF- $\alpha$ (right panel) in the supernatants were measured by ELISA. (B) IL-6 mRNA (left panel) and TNF- $\alpha$ mRNA (right panel) levels were quantitated with q-PCR. For $\mathbf{C}$ and $\mathbf{D}$, RAW264.7 cells were transfected with $100 \mathrm{nM}$ miR-124 inhibitor or negative control for $36 \mathrm{~h}$ and then stimulated with $100 \mathrm{ng} / \mathrm{ml}$ LPS with or without $5 \mathrm{mM}$ nicotine for $9 \mathrm{~h}$. (C) IL-6 (left panel) and TNF- $\alpha$ (right panel) in the supernatants were determined by ELISA. (D) IL- 6 mRNA (left panel) and TNF- $\alpha$ mRNA (right panel) levels were measured by q-PCR. Results are mean $\pm \operatorname{SD}(n=3)$. NS, not significant $(P>0.05)$; ${ }^{* *} P<0.01$ by Student's $t$-test. 
A

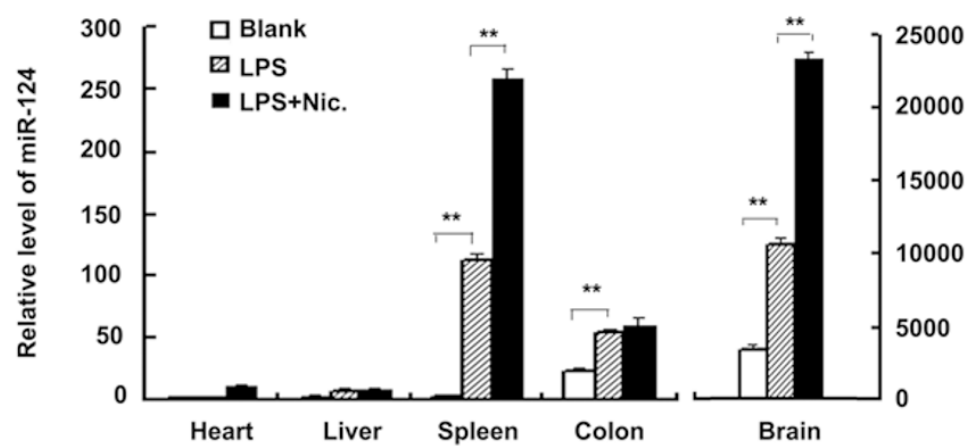

B

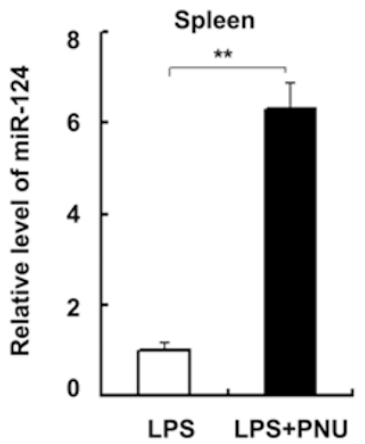

C

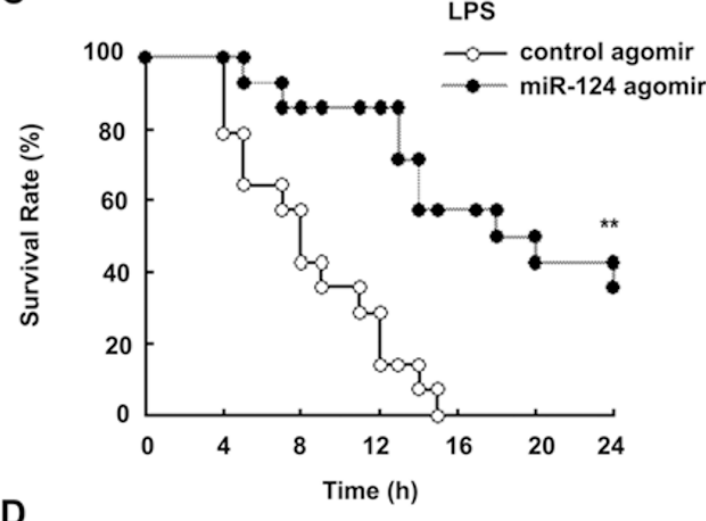

E

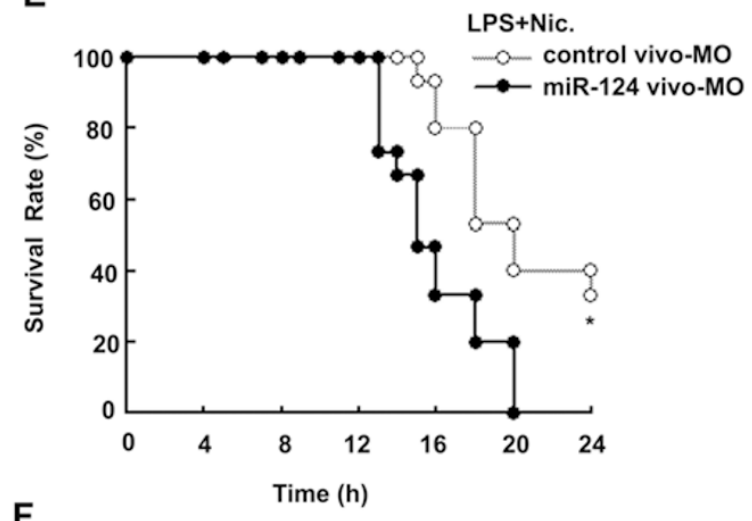

$\mathbf{F}$

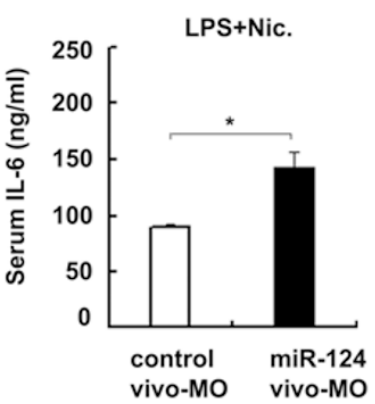

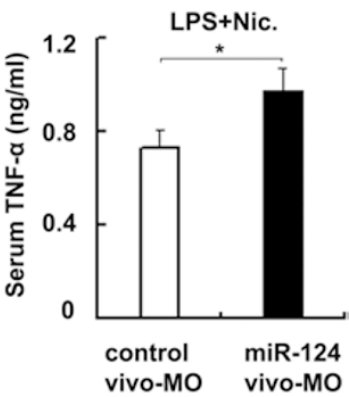

Figure 4 miR-124 is essential for the anti-inflammatory effect of the cholinergic pathway in LPS-induced septic mice. (A) qPCR of miR-124 in various tissues obtained from BALB/c mice injected intraperitoneally with $30 \mathrm{mg} / \mathrm{kg}$ LPS with or without $2 \mathrm{mg} / \mathrm{kg}$ nicotine for $3 \mathrm{~h}$. Data represent mean \pm SD $(n=6)$. (B) q-PCR of miR-124 in spleen obtained from BALB/c mice injected intraperitoneally with $30 \mathrm{mg} / \mathrm{kg}$ LPS in the presence or absence of $3 \mathrm{mg} / \mathrm{kg}$ PNU. Data represent mean \pm SD $(n=$

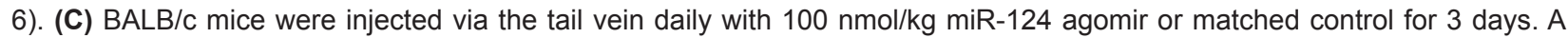
lethal dose of LPS $(30 \mathrm{mg} / \mathrm{kg})$ was then administered. The survival rate was recorded every $2 \mathrm{~h}(n=14)$. (D) ELISA detection of serum IL- 6 and TNF- $\alpha$ obtained from BALB/c mice $6 \mathrm{~h}$ after treatment as described in C. Results are mean \pm SD $(n=6)$. (E) BALB/c mice were injected via the tail vein daily with $12.5 \mathrm{mg} / \mathrm{kg}$ morpholino-conjugated miR-124 antisense (vivo-MO) or matched control for 3 days. They were then given intraperitoneally $30 \mathrm{mg} / \mathrm{kg} \mathrm{LPS}$ together with $2 \mathrm{mg} / \mathrm{kg}$ nicotine. The survival rate was recorded every $2 \mathrm{~h}(n=14)$. (F) ELISA detection of serum IL- 6 and TNF- $\alpha$ obtained from BALB/c mice $6 \mathrm{~h}$ after treatment as described in $\mathbf{E}$. Results are mean $\pm \mathrm{SD}(n=6) .{ }^{*} P<0.05$ and ${ }^{* *} P<0.01$ (Student's $t$-test in $\mathbf{A}, \mathbf{B}, \mathbf{D}$ and $\mathbf{F}$, logrank test in $\mathbf{C}$ and $\mathbf{E}$ ).

role in the cholinergic anti-inflammatory action, BALB/ c mice were injected intravenously with the miR-124 mimic agomir (Supplementary information, Figure S3C). As shown in Figure 4C and 4D, agomir significantly in- creased the survival rate and decreased serum IL- 6 and TNF- $\alpha$ levels of mice that were given a lethal dose of LPS. Under our experimental conditions, administration of $2 \mathrm{mg} / \mathrm{kg}$ nicotine also significantly increased the survival 
rate of LPS-injected mice (Supplementary information, Figure S3D). However, when these mice were given the antisence miR-124 vivo-morpholino through the tail vein to decrease miR-124 (Supplementary information, Figure S3E), the protective effect of nicotine on survival rate and production of serum IL- 6 and TNF- $\alpha$ was significantly attenuated (Figure 4E and 4F). These data indicate that miR124 plays an important role in the anti-shock effect of the cholinergic anti-inflammatory action.

\section{miR-124 targets STAT3 to attenuate LPS-induced IL-6 production}

Using TargetScan (http://www.targetscan.org) to search for targets of miR-124, we found that the $3^{\prime}$-UTR of mouse STAT3 mRNA contains two putative miR-124 target sites (Supplementary information, Figure S4A). To determine whether the stability of STAT3 mRNA is potentially regulated by miR-124, we constructed a reporter plasmid by inserting the cDNA corresponding to the 3'-UTR of mouse STAT3 mRNA into the 3'-region of the firefly luciferase gene. Similar plasmids containing the 3'-UTRs of IL- 6 and TNF- $\alpha$ mRNAs were also constructed, although both of them were not predicted to be the targets of miR-124. In cells transfected with the reporter plasmid containing 3'-UTR of STAT3 mRNA, the miR-124 mimic significantly decreased luciferase activity, whereas it did not significantly alter luciferase activity in cells transfected with reporter constructs that contain the $3^{\prime}$-UTR of IL-6 or TNF- $\alpha$ (Figure 5A). The effects of miR-124 on STAT3 were then examined in RAW264.7 cells. As shown in Figure 5B, the level of STAT3 decreased by approximately $50 \%$ when the cells were treated with the miR-124 mimic for $36 \mathrm{~h}$. Intriguingly, the level of STAT3 increased modestly when the cells were exposed to the miR-124 inhibitor (Figure 5B), suggesting that miR-124 is a modulator of STAT3 in the absence of inflammatory stimuli. Furthermore, akin to nicotine treatment, which reduced LPS-induced STAT3 phosphorylation (Tyr705) in both RAW264.7 cells and peritoneal macrophages (Supplementary information, Figure S4B), transfection of the miR-124 mimic also resulted in a significant decrease in the LPS-induced STAT3 tyrosine phosphorylation (Figure 5C). As both miR-124 mimic and inhibitor did not change the mRNA level of STAT3 in macrophages (Supplementary information, Figure S4C), these data indicate that miR-124 likely targets STAT3 through translational inhibition.

To assess whether STAT3 is required for LPS-induced cytokine production, specific siRNA was used to knock down STAT3 in RAW264.7 cells (Supplementary information, Figure S4D). As shown in Figure 5D, STAT3 siRNA significantly reduced LPS-induced IL- 6 produc- tion at both mRNA and protein levels. However, STAT3 knockdown did not affect LPS-induced TNF- $\alpha$ protein and mRNA production. In these STAT3-knockdown cells, the miR-124 mimic did not further reduce the level of LPS-induced IL- 6 production, although it still decreased TNF- $\alpha$ production (Figure 5E). Furthermore, LPS induced the production of IL-6, but not that of TNF- $\alpha$ in mouse embryo fibroblasts (MEFs). As shown in Figure 5F, LPS could not induce IL-6 and its mRNA in MEFs from STAT3-deficient mice (Supplementary information, Figure S4E). These results demonstrate that STAT3 is critical for IL-6 production in response to LPS and that miR-124 can target STAT3 to inhibit IL-6 production at the transcriptional level.

\section{miR-124 targets TACE to modulate mature TNF- $\alpha$ pro- duction}

As miR-124 reduced LPS-induced TNF- $\alpha$ production without decreasing the level and stability of its mRNA (Supplementary information, Figure S5A), the translation of TNF- $\alpha$ mRNA or post-translational processing might be its target. It has been shown that TNF- $\alpha$ is synthesized as a membrane-anchored precursor (pro-TNF- $\alpha$ ) and released from cells by the action of proteases, including TACE, which is regarded as the most important TNF sheddase [26]. Mice lacking tissue inhibitor of matrix metalloproteinases 3 (TIMP3), the endogenous inhibitor of TACE, have an exacerbated response to LPS [27], whereas TACE inactivation in mice offers strong protection from septic shock by preventing a TNF- $\alpha$ increase in serum [28]. Therefore, we examined whether nicotine affects the processing of pro-TNF- $\alpha$. As shown in Figure $6 \mathrm{~A}$, nicotine treatment significantly increased pro-TNF- $\alpha$ and decreased mature TNF- $\alpha$ production in LPS-treated macrophages. Furthermore, transfection of the miR-124 mimic also led to the accumulation of pro-TNF- $\alpha$ and a decrease of mature TNF- $\alpha$ in LPS-stimulated RAW264.7 cells, indicating that miR-124 might mediate the cholinergic inhibiting action on TNF- $\alpha$ production by preventing the maturation of TNF- $\alpha$.

Interestingly, it was indicated by TargetScan that the 3'-UTR of TACE contains two putative miR-124 target sites (Supplementary information, Figure S5B). The wild-type and mutant 3'-UTR luciferase reporter constructs of TACE were made. As shown in Figure 6B, the miR-124 mimic significantly decreased while the inhibitor significantly increased luciferase activity in HEK293 cells (which have nearly 45 times higher level of miR-124 than that in RAW264.7 macrophages, data not shown) transfected with the wild-type TACE 3'UTR reporter. However, these effects were abolished when cells were transfected with mutant TACE 3 '- 
A

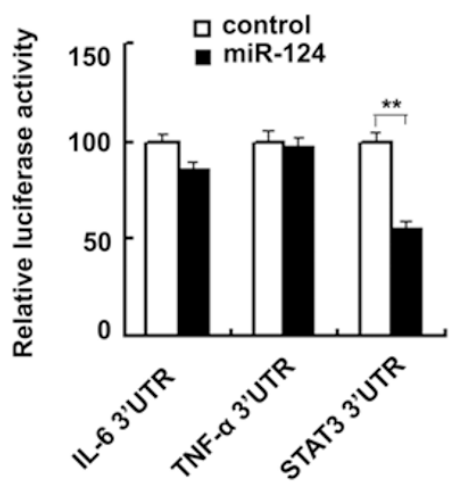

B

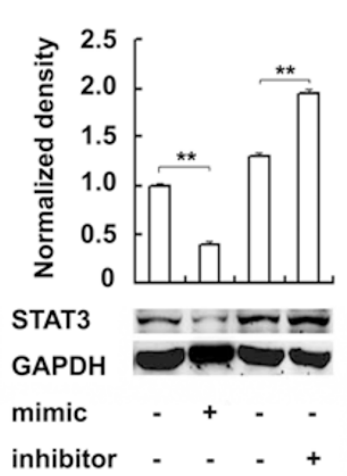

C

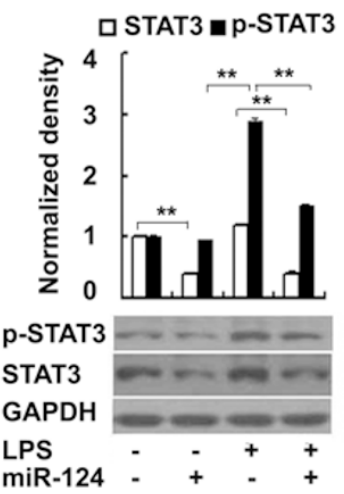

D
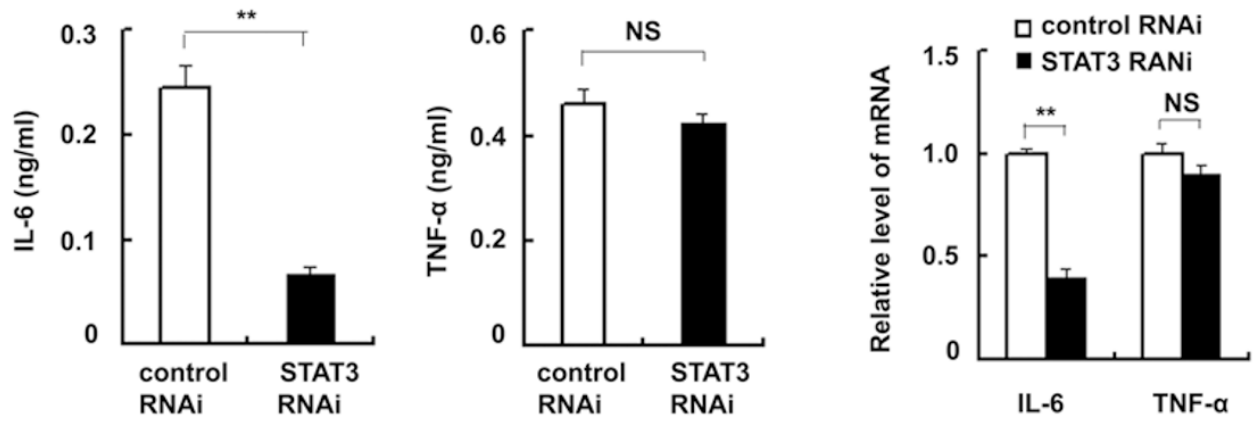

E
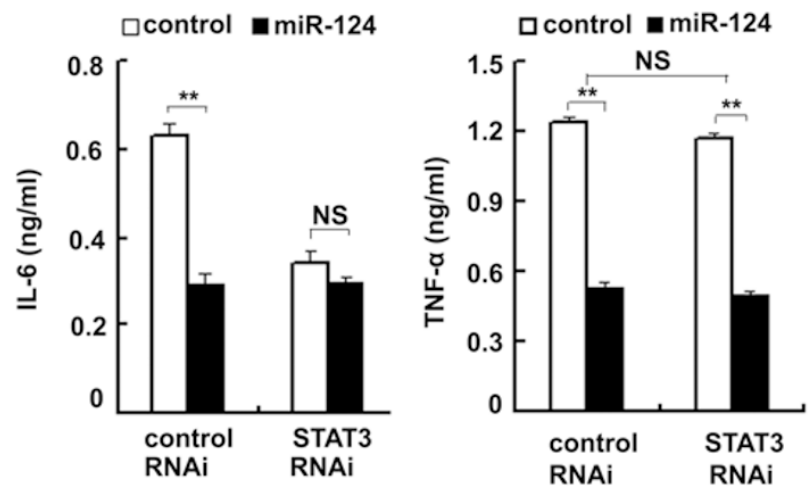

$\mathbf{F}$
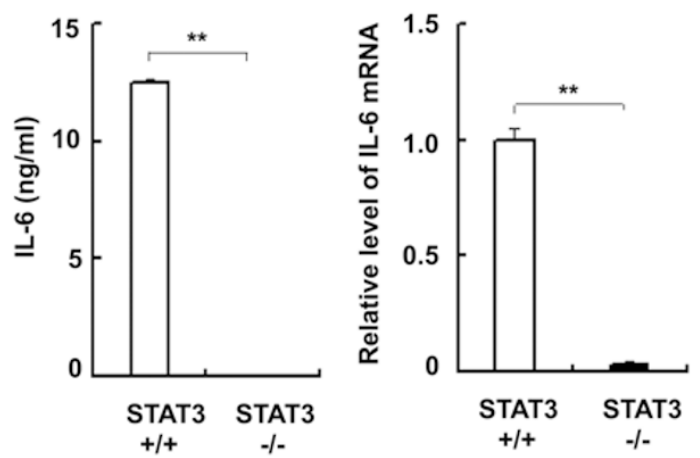

Figure 5 miR-124 targets STAT3 to inhibit IL-6 production. (A) Luciferase activity of HEK293 cells $24 \mathrm{~h}$ after transfection with the reporter containing 3'-UTR of STAT3, IL-6 or TNF- $\alpha$ mRNA and miR-124 mimic. (B) Western blotting of STAT3 protein in RAW264.7 cells transfected with miR-124 mimic or inhibitor and their corresponding controls for $36 \mathrm{~h}$. (C) Western blotting of STAT3 and Y705-phosphorylated STAT3 in RAW264.7 cells transfected with the miR-124 mimic or negative control for $36 \mathrm{~h}$, and then stimulated with vehicle or $100 \mathrm{ng} / \mathrm{ml}$ LPS for $9 \mathrm{~h}$. (D) ELISA and q-PCR detection of IL-6 or TNF- $\alpha$ in RAW264.7 cells transfected with STAT3 siRNA or control siRNA for $48 \mathrm{~h}$ and then treated with $100 \mathrm{ng} / \mathrm{ml}$ LPS for $9 \mathrm{~h}$. (E) ELISA detection of IL-6 or TNF- $\alpha$ in the supernatants of RAW264.7 cells transfected with STAT3 siRNA and miR-124 mimic for $36 \mathrm{~h}$ and then treated with $100 \mathrm{ng} / \mathrm{ml}$ LPS for $9 \mathrm{~h}$. (F) ELISA and q-PCR detection of IL- 6 in STAT3 ${ }^{+/+}$or STAT3 ${ }^{-1-}$ MEFs stimulated with $1 \mu \mathrm{g} / \mathrm{ml}$ LPS for $9 \mathrm{~h}$. For $\mathbf{B}$ and $\mathbf{C}$, data are representative of three independent experiments. For $\mathbf{A}$ and $\mathbf{D}-\mathbf{F}$, data represent mean $\pm \mathbf{S D}(n=3)$. NS, not significant $(P>0.05) ;{ }^{* *} P<0.01$ by Student's $t$-test.

UTR reporter. Furthermore, both nicotine and the miR124 mimic decreased TACE expression in RAW264.7 cells (Figure 6C), indicating that miR-124 can regulate
TACE in cells. To further determine whether TACE is involved in the action of miR-124, specific siRNA was used to knock down TACE (Supplementary information, 

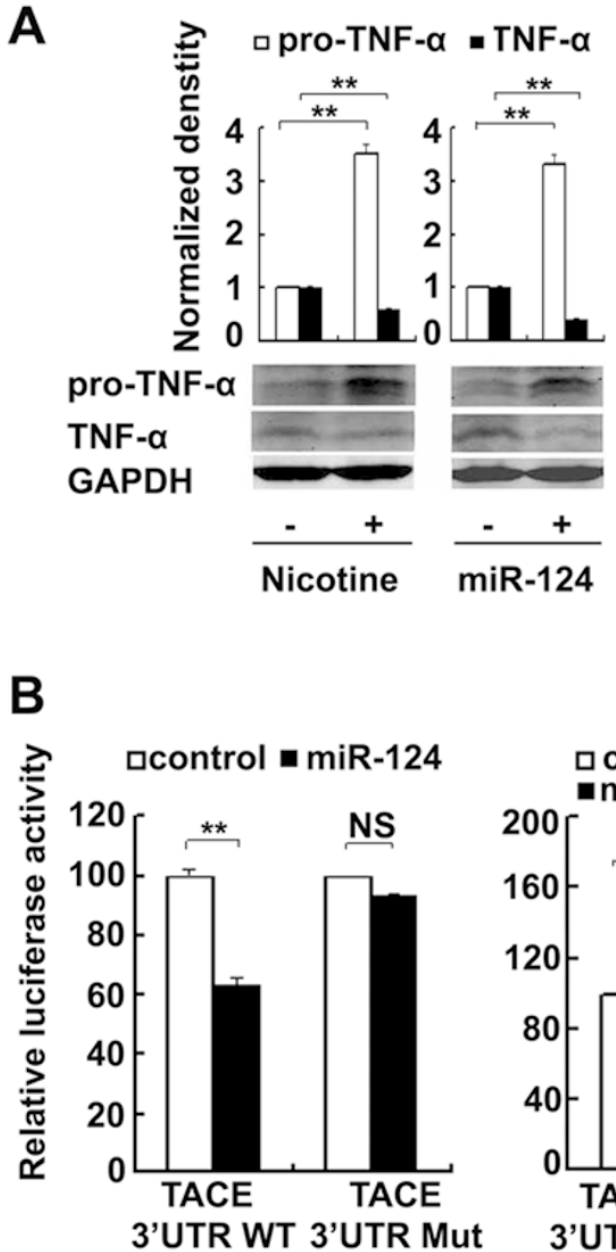

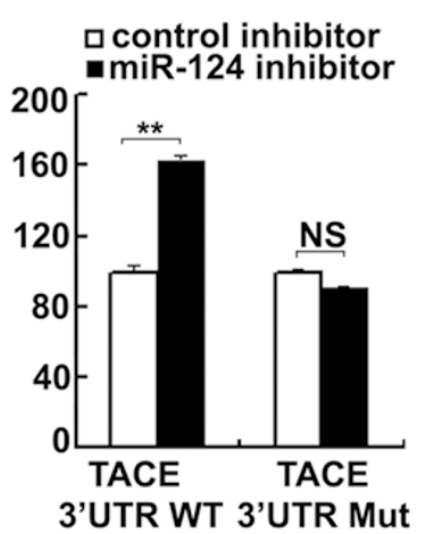

D

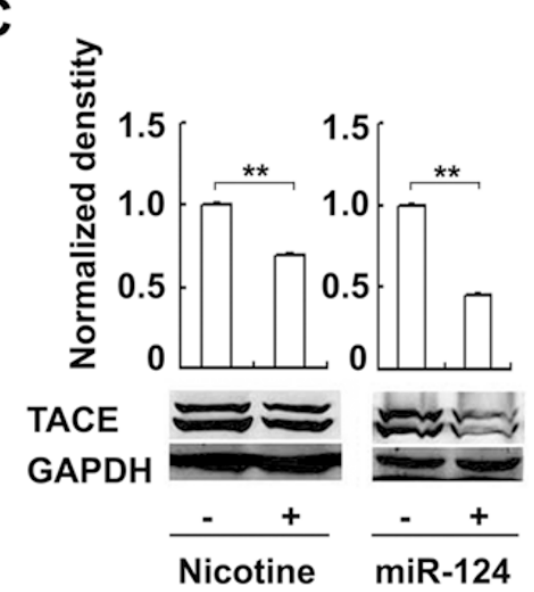

Figure 6 miR-124 targets TACE to inhibit TNF- $\alpha$ production. (A) Western blotting of pro-TNF- $\alpha$ and TNF- $\alpha$ proteins in RAW264.7 cells incubated with $5 \mathrm{mM}$ nicotine for 10 min or transfected with miR-124 mimic for $36 \mathrm{~h}$, and then stimulated with $100 \mathrm{ng} / \mathrm{ml}$ LPS for $9 \mathrm{~h}$. (B) Luciferase activity of HEK293 cells co-transfected with the miR-124 mimic or inhibitor and the luciferase reporter of TACE 3'-UTR wild type (WT) or Mutant (Mut) for $24 \mathrm{~h}$. (C) Western blotting of TACE protein in RAW264.7 cells treated as described in A. The two bands detected may represent processing or glycosylation of TACE as indicated by the Ab manufacturer. (D) ELISA detection of TNF- $\alpha$ in the supernatants of RAW264.7 cells transfected with TACE siRNA and miR-124 mimic for $36 \mathrm{~h}$ and then treated with $100 \mathrm{ng} / \mathrm{ml}$ LPS for $9 \mathrm{~h}$. For $\mathbf{A}$ and $\mathbf{C}$, data are representative of three independent experiments. For $\mathbf{B}$ and $\mathbf{D}$, data represent mean \pm SD $(n=3)$. NS, not significant; ${ }^{* \star} P<0.01$ by Student's $t$-test.

Figure S5C). As shown in Figure 6D, transfection of a suboptimal amount of miR-124 mimic decreased LPSinduced TNF- $\alpha$ production by $\sim 25 \%$, which was not further decreased by knockdown of TACE. As miR-124 did not change the level of TACE mRNA (Supplementary information, Figure S5D), these results suggest that miR124 inhibits the translation of TACE mRNA to modulate TNF- $\alpha$ production.

\section{Discussion}

Despite tremendous progress in numerous aspects of the medical sciences, sepsis remains one of the leading causes of death in the clinic. Many studies have demonstrated that dysregulated production of pro-inflammatory cytokines plays a critical role in triggering sepsis-induced circulation shock and multiple organ failure, which are largely responsible for the mortality [29]. Biologics that neutralize pro-inflammatory cytokines (i.e., anti-TNF antibodies, recombinant soluble IL-1 and TNF-receptors) have been successfully used in the treatment of certain inflammatory diseases, including rheumatoid arthritis, Crohn's disease, ankylosing spondylitis, and psoriasis [30-32]. However, dozens of clinical trials attempting to address sepsis-associated inflammation and organ dysfunction achieved only limited, if any, success in improv- 
ing the outcomes of severe sepsis [29]. There are at least two potential explanations for these failures: (1) multiple cytokines are involved in severe sepsis; (2) each cytokine may exert both protective and damaging effects during sepsis. Therefore, it has been proposed that the most important issue now is to understand the anti-inflammatory response of the host [33]. A series of elegant studies by Tracey and colleagues identified the cholinergic antiinflammatory pathway [34]. Three treatment options, i.e., electrical stimulation of the vagus nerve, pharmacological agonists of $\alpha 7 \mathrm{nAChR}$, and modulation of neuron function, have been found effective in various disease models, including sepsis, arthritis, and ischemia-reperfusion injuries [34]. However, vagus nerve stimulation in humans is an invasive procedure and is not feasible under many circumstances. Although nicotine has been used with some success in the treatment of ulcerative colitis, which featured high STAT3 phosphorylation [35], it is not specific for $\alpha 7 \mathrm{nAChR}$. The high dose needed to generate anti-septic effects is associated with severe side effects and toxicity. Therefore, exploring the mechanisms of signal transduction through $\alpha 7 \mathrm{nAChR}$ may provide more specific and effective targets for therapeutic interventions that modulate inflammatory responses.

Since the initial discovery of their regulatory roles in the development of the nematode, miRNAs have emerged as key modulators in many biological processes, including the inflammatory response. Interestingly, it has been shown that TLR/NF- $\kappa B$ activation is capable of inducing multiple miRNAs, including miR-146a and miR155 [21, 22]. While miR-155 targets negative regulators such as SHIP and SOCS1 and enhances inflammatory responses, miR-146a downregulates TRAF6 and IRAK1, which participate in TLR4-mediated signal transduction, and reduces pro-inflammatory cytokine production, demonstrating that multiple miRNAs can modulate one signal pathway and a single miRNA can affect multiple molecules in the same pathway. We have found in this study that the cholinergic signal-induced miR-124 can target two different proteins that are not directly related to TLR4 signaling, but indirectly affect the outcomes of LPS stimulation, revealing an additional layer of complexity of miRNA actions. It is worth noting that miR124 can also regulate the expression of $\mathrm{I} \kappa \mathrm{B} \zeta$ [36], which has been found to be indispensible for the transactivation of a subset of NF- $\kappa B$ target genes, including IL-6 and IL-12p40, but not TNF and NO in macrophages [37]. Whether the inhibition of I $\mathrm{I} B \zeta$ by miR-124 occurs in LPS-stimulated macrophages and whether this inhibition plays a role in the cholinergic anti-inflammatory action remain to be further investigated. As previously reported and shown in Figure 4, miR-124 is highly expressed in the central nervous system and microglia, which function as macrophages in the CNS. It has been shown recently that miR-124 can target transcription factor C/EBP- $\alpha$ and promote microglia quiescence [20], suggesting that $\mathrm{C} / \mathrm{EBP}-\alpha$ might also be involved in the cholinergic antiinflammatory action.

The intracellular mechanisms of the cholinergic antiinflammatory action have been investigated in a number of different systems. In HBE16 airway epithelial cells, it was shown that nicotine reduces TNF- $\alpha$ expression at the transcriptional level by blocking NF- $\mathrm{kB}$ activation [38]. In RAW267.4 cells, it was found that nicotine inhibits LPS-induced NO synthesis by suppressing p42/44 MAPK and S6K1-mediated STAT3 phosphorylation at serine 727 [39]. The cholinergic agonist nicotine and GTS-21 also suppress IL-6-mediated endothelial cell activation, presumably by decreasing the phosphorylation of JAK2 and STAT3 [40]. Intriguingly, it was reported that engagement of $\alpha 7 \mathrm{nAChR}$ is able to activate STAT3, which is responsible for the inhibition of LPSinduced production of pro-inflammatory cytokines [41]. However, subsequent studies participated by the same group and our results have shown that LPS-induced STAT3 phosphorylation is inhibited by $\alpha 7 \mathrm{nAChR}$ activation (Figure 5) [42]. There are contradictory reports regarding whether STAT3 and its phosphorylation can directly regulate TNF- $\alpha$ production in macrophages following LPS stimulation, which is at least partially due to the production of multiple cytokines that might crosstalk [42-46]. The ability of miR-124, which is induced modestly by LPS alone (Figure $2 \mathrm{C}$ ), to target STAT3 and TACE and affect TNF- $\alpha$ secretion suggests that it could connect different pathways. In contrast, it has been demonstrated that IL-6 activates STAT3 to regulate the expression of target genes, and activation of STAT3 upregulates IL-6 in a number of cancer cells [47], forming a positive feedback loop. The significance of this loop is illustrated by the finding that STAT3-deficient MEFs produced little IL-6 after LPS treatment (Figure 5). Downregulation of STAT3 by miR-124 appears to restrict the positive feedback, leading to a reduction in IL-6 production (Figure 7). Consistent with our results, it has been shown very recently that miR-124 can target STAT3 and regulate the differentiation of bone marrowderived mesenchymal cells [48]. Additionally, a study in hepatocytes indicated that miR-124 also targets IL-6 receptor [49], suggesting that regulating the expression of the IL-6 receptor may also restrict the positive feedback loop. It would be interesting to further examine whether the lack of the receptor will affect LPS-induced IL-6 production and whether miR-124 can target the receptor in macrophages. 


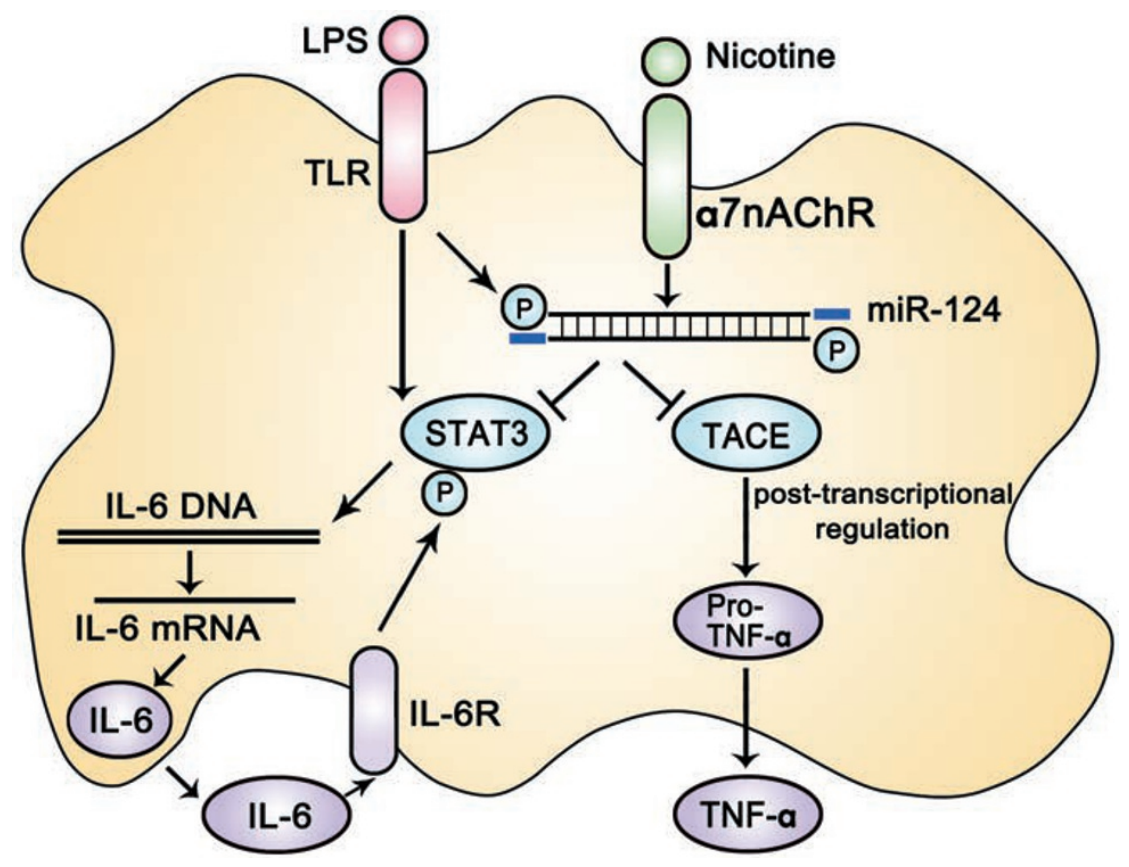

Figure 7 miR-124 mediates the cholinergic anti-inflammatory action through targeting STAT3 and TACE. Nicotine upregulates miR-124 expression through activating $\alpha 7 n A C h R$ in LPS-stimulated macrophages. STAT3 is critical for IL-6 production in response to LPS. Its activation leads to increased transcription and production of IL-6, which in turn induces STAT3 phosphorylation via IL-6 receptor and further increases IL-6 transcription, forming a positive feedback loop. miR-124 targets STAT3, and decreases STAT3 and its phosphorylation, resulting in the reduction of IL-6 at the transcription level. In addition, miR-124 targets TACE to modulate TNF- $\alpha$ maturation.

\section{Materials and Methods}

\section{Reagents}

LPS, nicotine, methyllycaconitine (MLA) and PNU282987 (PNU) were purchased from Sigma (St Louis, MO, USA). Antibodies specific to STAT3 and phospho-STAT3 (Tyr705) were from Cell Signaling (Danvers, MA, USA). Anti-Dicer antibody was from IMGENEX (San Diego, CA, USA). Anti-GAPDH antibody was from Protein Tech (Chicago, IL, USA). Anti-TACE antibody was from AbCam (Cambridge, UK). The miR-124 mimic and miR-124 inhibitor (mmu-miR-124 mature sequence: 5'-UAA GGC ACG CGG UGA AUG CC-3') for in vitro studies were from Dharmacon (Lafayette, CO, USA). For in vivo studies, the miR-124 agomir (modified miR-124 mimic) and the negative control were from RiboBio (Guangzhou, China), and the antisense miR-124 vivo-morpholino (5'-GGC ATT CAC CGC GTG CCT TAA TTG T-3') and the control vivo-morpholino (5'-GGC AAT GAC CCC GTC CCT TAA TTC T-3') were from GeneTools (Philomath, OR, USA).

\section{Cell culture and transfection}

Mouse macrophage cell line RAW264.7 and human HEK293 cell line were obtained from American Type Culture Collection (ATCC, Manassas, VA, USA) and cultured as described [50]. These cells were transfected with Lipofectamine 2000 (Invitrogen, Carlsbad, CA, USA) according to the manufacturer's instructions. Enriched thioglycollate broth (Sigma)-elicited mouse peritoneal macrophages from wild-type C57BL/6 and $\alpha 7 \mathrm{nAChR}$-deficient mice were prepared and cultured as previously described [51]. STAT3-deficient MEFs were obtained from Dr Luis G Rodriguez (SAIC, MD, USA). Wild-type MEFs were prepared from E13.5 mouse embryos according to standard procedures. MEFs were cultured in DMEM supplemented with $10 \%$ FBS, 100 units $/ \mathrm{ml}$ of penicillin and $100 \mu \mathrm{g} / \mathrm{ml}$ of streptomycin in a humidified incubator with $5 \% \mathrm{CO}_{2}$.

\section{Animals}

BALB/c and C57BL/6 mice (18-22 g) were purchased from Sino-British SIPPR/BK Laboratory Animals (Shanghai, China). The $\alpha 7 \mathrm{nAChR}-$ deficient mice (B6.129S7-Chrna7tm1Bay, Stock Number: 00323) were obtained from Jackson Laboratory (Bar Harbor, MA, USA). Mice were 5-6 weeks of age at the start of the experiments. All animals were maintained in animal rooms at $22{ }^{\circ} \mathrm{C}$ on a 12-h light/dark cycle with free access to water and a standard rodent diet. All animal experiments were undertaken in accordance with the National Institute of Health's "Guide for the Care and Use of Laboratory Animals", with the approval of the Scientific Investigation Board of Second Military Medical University.

\section{RNA interference}

The Dicer-specific siRNAs were 5'-GCC GAU CUC UAA UUA CGU ATT-3' (sense) and 5'-UAC GUA AUU AGA GAU CGG CGC-3' (antisense). The STAT3-specific siRNAs were 5'GGG UGA AAU UGA CCA GCA ATT-3' (sense) and 5'-UUG 
CUG GUC AAU UUC ACC CAA-3' (antisense). The TACE-specific siRNAs were 5'-GUA CGU CGA UGC AGA GCA A dTdT-3' (sense) and 5'-UUG CUC UGC AUC GAC GUAC TdTd-3' (antisense). The scrambled control RNA sequences were $5^{\prime}$-UUC UCC GAA CGU GUC ACG UTT-3' (sense) and 5'-ACG UGA CAC GUU CGG AGA ATT-3' (antisense). These siRNA duplexes were transfected into RAW264.7 cells using Lipofectamine 2000.

\section{3'-UTR luciferase reporter assays}

The 3'-UTR luciferase reporter constructs of STAT3, TNF- $\alpha$ and IL- 6 were made by cloning the 3 '-UTR region of the corresponding mRNA into the SpeI and HindIII site of pGL3-promoter construct (Promega, Madison, WI, USA). The primers for 3'-UTR of STAT3 mRNA were 5'-GAC TAG TCT CCT TTT TCA GCA GCT CGG GGT TGG-3' (sense) and 5'-CCC AAG CTT CAG TTC GTC TTG GAG ACA ATG TCC TCA CTG C-3' (antisense); for 3'-UTR of IL-6 mRNA were 5'-GAC TAG TTG CGT TAT GCC TAA GCA TAT CAG TTT-3' (sense) and 5'-CCC AAG CTT CAC TGG TTT TTA AAT ATA ATA TAA TTT ATT TG-3' (antisense); for 3'-UTR of TNF- $\alpha$ mRNA were 5'-GAC TAG TAG GGA ATG GGT GTT CAT CCA TTC TC-3' (sense) and 5'-CCC AAG CTT CTT TTC CAA GCG ATC TTT ATT TCT CTC-3' (antisense). The wild-type and mutant TACE 3 '-UTR luciferase reporters were provided by RiboBio. Briefly, 3'-UTR region of the mouse TACE mRNA and its mutant (the miR-124 site in the TACE 3'-UTR was mutated) was cloned into the XhoI and NotI site of pmiR-RBREPORT $^{\mathrm{TM}}$ (Promega). The following primers (mutated bases in bold and italic) were used: TACE-3'-UTR wild type, 5'-CCG CTC GAG TGG GGA ACC TTG GCC TGC TCT AG-3' (sense) and 5'-GAA TGC GGC CGC TTC ATG TTG GTA GCC ACA AAC ATT CTG TG-3' (antisense). TACE-3'-UTR mutant, primer 1: 5'ACT GTT $\boldsymbol{A} \boldsymbol{C} \boldsymbol{G} \boldsymbol{T} \boldsymbol{A} \boldsymbol{T}$ AAA AAA AAA AAT CAA TAT TGG GC$3^{\prime}$ (sense) and 5'-TTT TTT T $\boldsymbol{A} \boldsymbol{T} \boldsymbol{A} \boldsymbol{C} \boldsymbol{G} \boldsymbol{T A A}$ CAG TTT AAA GAC GAC AC-3' (antisense); primer 2: 5'-CAA GCC TAG TTC ATG TCT CTC CTG AGG ACG CC-3' (sense) and 5'-GAG AGA CAT $\boldsymbol{G A \boldsymbol { A }} \boldsymbol{C T A}$ GGC TTG GTT AAC TGT CC-3' (antisense). All the constructs were confirmed by sequencing analysis. HEK293 cells were cotransfected with luciferase reporter plasmid and the miR124 mimic or inhibitor. After $24 \mathrm{~h}$, luciferase activities were measured using the Dual-Luciferase Reporter Assay System (Promega) according to the manufacturer's instructions.

\section{RNA quantification}

Total RNA, containing miRNA, was extracted with TRIzol reagent (Invitrogen) following the manufacturer's instructions. Real-time quantitative RT-PCR analysis was performed using the Taqman MicroRNA Assays (ABI, Carlsbad, CA, USA) and SYBR RT-PCR kits (Takara Shuzo, Otsu, Japan). For miRNA analysis, Taqman MicroRNA Assays were performed. The relative expression level of miRNAs was normalized to that of internal control sno234 by using a $2^{-\Delta \Delta C t}$ cycle threshold method. The primers for TNF- $\alpha$ were: 5'-AAG CCT GTA GCC CAC GTC GTA-3' (sense) and 5'-GGC ACC ACT AGT TGG TTG TCT TTG-3' (antisense); for IL-6 were: 5'-TAG TCC TTC CTA CCC CAA TTT CC-3' (sense) and 5'-TTG GTC CTT AGC CAC TCC TTC-3' (antisense); for STAT3 were: 5'-TGC TTG TCG GTT GGA GGT GT-3' (sense) and 5'-GGG AAA GGA AGG CAG GTT GA-3' (antisense); for TACE were: 5'-AAC TTG AGA GTC GTG GTG GTG-3' (sense) and 5'-ACA AAC CTC CAA AGT GGC TCT-3' (antisense); for $\beta$-actin were: 5'-AGT GTG ACG TTG ACA TCC GT-3' (sense) and 5'-GCA GCT CAG TAA CAG TCC GC-3' (antisense). Data were normalized by the levels of $\beta$-actin expression in each sample.

\section{Enzyme-linked immunosorbent assay}

IL- 6 and TNF- $\alpha$ levels in the culture supernatants and sera were measured with enzyme-linked immunosorbent assay (ELISA) kits according to the manufacturer's protocols (R\&D Systems, Minneapolis, MN, USA).

\section{Immunoblotting}

RAW264.7 cells or peritoneal macrophages were lysed with MPER protein extraction reagent (Pierce, Rockford, IL, USA) supplemented with the protease inhibitor mixture (CalBiochem, San Diego, CA, USA). After centrifugation, proteins in the supernatant were separated by SDS-PAGE and transferred onto nitrocellulose membranes. Immunoblottings were performed as described previously.

\section{Statistical analysis}

Data are expressed as mean $\pm \mathrm{SD}$. Statistical significance was determined using a Student's $t$-test. Survival data were analyzed by constructing Kaplan-Meier plots and using a log-rank test.

\section{Acknowledgments}

We thank Dr Alan O Perantoni (National Institutes of Health, USA) for critical reading of the manuscript, and Dr Luis G Rodriguez for the STAT3 ${ }^{-/-}$MEFs. This work was supported by the National Key Basic Research Program of China (973 Program; 2009CB521901 to Ding-Feng Su) and the National Natural Science Foundation of China (30973525 and 81273606 to Xia Liu).

\section{References}

1 Medzhitov R. Origin and physiological roles of inflammation. Nature 2008; 454:428-435.

2 Nathan C. Points of control in inflammation. Nature 2002; 420:846-852.

3 Webster JI, Tonelli L, Sternberg EM. Neuroendocrine regulation of immunity. Annu Rev Immunol 2002; 20:125-163.

4 Borovikova LV, Ivanova S, Zhang M, et al. Vagus nerve stimulation attenuates the systemic inflammatory response to endotoxin. Nature 2000; 405:458-462.

5 Ulloa $L$. The vagus nerve and the nicotinic anti-inflammatory pathway. Nat Rev Drug Discov 2005; 4:673-684.

6 Rosas-Ballina M, Olofsson PS, Ochani M, et al. Acetylcholinesynthesizing $\mathrm{T}$ cells relay neural signals in a vagus nerve circuit. Science 2011; 334:98-101.

7 Pena G, Cai B, Ramos L, Vida G, Deitch EA, Ulloa L. Cholinergic regulatory lymphocytes re-establish neuromodulation of innate immune responses in sepsis. J Immunol 2011; 187:718725 .

8 Wang $\mathrm{H}$, Liao H, Ochani M, et al. Cholinergic agonists inhibit HMGB1 release and improve survival in experimental sepsis. Nat Med 2004; 10:1216-1221.

9 Marrero MB, Bencherif M, Lippiello PM, Lucas R. Application 
of alpha7 nicotinic acetylcholine receptor agonists in inflammatory diseases: an overview. Pharm Res 2011; 28:413-416.

10 Zhao M, He X, Bi XY, Yu XJ, Gil Wier W, Zang WJ. Vagal stimulation triggers peripheral vascular protection through the cholinergic anti-inflammatory pathway in a rat model of myocardial ischemia/reperfusion. Basic Res Cardiol 2013; 108:345.

11 Wessler I, Kirkpatrick CJ. Acetylcholine beyond neurons: The non-neuronal cholinergic system in humans. $\mathrm{Br} J$ Pharmacol 2008; 154:1558-1571.

12 Khiroug L, Giniatullin R, Klein RC, Fayuk D, Yakel JL. Functional mapping and $\mathrm{Ca} 2+$ regulation of nicotinic acetylcholine receptor channels in rat hippocampal CA1 neurons. J Neurosci 2003; 23:9024-9031.

13 Bitner RS, Bunnelle WH, Anderson DJ, et al. Broad-spectrum efficacy across cognitive domains by alpha7 nicotinic acetylcholine receptor agonism correlates with activation of ERK/2 and CREB phosphorylation pathways. J Neurosci 2007; 27:10578-10587.

14 Wang H, Yu M, Ochani M, et al. Nicotinic acetylcholine receptor alpha7 subunit is an essential regulator of inflammation. Nature 2003; 421:384-388.

15 Huang Y, Shen XJ, Zou Q, Wang SP, Tang SM, Zhang GZ. Biological functions of microRNAs: a review. J Physiol Biochem 2011; 67:129-139.

16 Karginov FV, Conaco C, Xuan Z, et al. A biochemical approach to identifying microRNA targets. Proc Natl Acad Sci USA 2007; 104:19291-19296.

17 O'Connell RM, Rao DS, Baltimore D. MicroRNA regulation of inflammatory responses. Annu Rev Immunol 2012; 30:295312.

18 Suzuki HI, Yamagata K, Sugimoto K, Iwamoto T, Kato S, Miyazono K. Modulation of microRNA processing by $\mathrm{p} 53$. Nature 2009; 460:529-533.

19 Waldburger JM, Boyle DL, Pavlov VA, Tracey KJ, Firestein GS. Acetylcholine regulation of synoviocyte cytokine expression by the alpha7 nicotinic receptor. Arthritis Rheum 2008; 58:3439-3449.

20 Ponomarev ED, Veremeyko T, Barteneva N, Krichevsky AM, Weiner HL. MicroRNA-124 promotes microglia quiescence and suppresses EAE by deactivating macrophages via the $\mathrm{C} /$ EBP- $\alpha$-PU.1 pathway. Nat Med 2011; 17:64-70.

21 Tsitsiou E, Lindsay MA. MicroRNAs and the immune response. Curr Opin Pharmacol. 2009; 9:514-520.

22 Tili E, Michaille JJ, Cimino A, et al. Modulation of mir-155 and mir-125b levels following lipopolysaccharide/TNF-alpha stimulation and their possible roles in regulating the response to endotoxin shock. J Immunol 2007; 179:5082-5089.

23 Quinn SR, O'Neill LA. A trio of microRNAs that control Tolllike receptor signalling. Int Immunol 2011; 23:421-425.

24 Huston JM, Ochani M, Rosas-Ballina M, et al. Splenectomy inactivates the cholinergic antiinflammatory pathway during lethal endotoxemia and polymicrobial sepsis. J Exp Med 2006; 203:1623-1628.

25 Rosas-Ballina M, Ochani M, Parrish WR, et al. Splenic nerve is required for cholinergic antiinflammatory pathway control of TNF in endotoxemia. Proc Natl Acad Sci USA 2008; 105:11008-11013.

26 Moss ML, Jin SL, Milla ME, et al. Cloning of a disintegrin metalloproteinase that processes precursor tumour-necrosis factor-alpha. Nature 1997; 385:733-736.

27 Smookler DS, Mohammed FF, Kassiri Z, Duncan GS, Mak TW, Khokha R. Tissue inhibitor of metalloproteinase 3 regulates TNF-dependent systemic inflammation. J Immunol 2006; 176:721-725.

28 Horiuchi K, Kimura T, Miyamoto T, et al. Cutting edge: TNFalpha-converting enzyme (TACE/ADAM17) inactivation in mouse myeloid cells prevents lethality from endotoxin shock. J Immunol 2007; 179:2686-2689.

29 Hotchkiss RS, Karl IE. The pathophysiology and treatment of sepsis. N Engl J Med. 2003; 348:138-150.

30 Feldmann M. Development of anti-TNF therapy for rheumatoid arthritis. Nat Rev Immunol 2002; 2:364-371.

31 Van Assche G, Rutgeerts P. Anti-TNF agents in crohn's disease. Expert Opin Investig Drugs 2000; 9:103-111.

32 Sims JE, Smith DE. The IL-1 family: regulators of immunity. Nat Rev Immunol 2010; 10:89-102.

33 Fry DE. Sepsis, systemic inflammatory response, and multiple organ dysfunction: the mystery continues. Am Surg 2012; 78: $1-8$.

34 Andersson U, Tracey KJ. Reflex principles of immunological homeostasis. Annu Rev Immunol 2012; 30:313-335.

35 Lakhan SE, Kirchgessner A. Anti-inflammatory effects of nicotine in obesity and ulcerative colitis. J Transl Med 2011; 9:129.

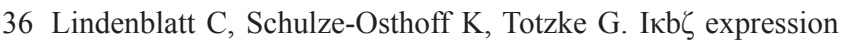
is regulated by miR-124a. Cell Cycle 2009; 8:2019-2023.

37 Yamamoto M, Yamazaki S, Uematsu S, et al. Regulation of Toll/IL-1-receptor-mediated gene expression by the inducible nuclear protein IkappaBzeta. Nature 2004; 430:218-222.

38 Li Q, Zhou XD, Kolosov VP, Perelman JM. Nicotine reduces TNF- $\alpha$ expression through a $\alpha 7 \mathrm{nAChR/MyD88/NF- \kappa b} \mathrm{path-}$ way in HBE16 airway epithelial cells. Cell Physiol Biochem 2011; 27:605-612.

39 Park SY, Baik YH, Cho JH, Kim S, Lee KS, Han JS. Inhibition of lipopolysaccharide-induced nitric oxide synthesis by nicotine through S6K1-p42/44 MAPK pathway and STAT3 (Ser 727) phosphorylation in Raw 264.7 cells. Cytokine 2008; 44:126-134.

40 Chatterjee PK, Al-Abed Y, Sherry B, Metz CN. Cholinergic agonists regulate JAK2/STAT3 signaling to suppress endothelial cell activation. Am J Physiol Cell Physiol 2009; 297:C1294C1306.

41 de Jonge WJ, van der Zanden EP, The FO, et al. Stimulation of the vagus nerve attenuates macrophage activation by activating the Jak2-STAT3 signaling pathway. Nat Immunol 2005; 6:844851.

42 Pena G, Cai B, Liu J, et al. Unphosphorylated STAT3 modulates $\alpha 7$ nicotinic receptor signaling and cytokine production in sepsis. Eur J Immunol 2010; 40:2580-2589.

43 Samavati L, Rastogi R, Du W, Huttemann M, Fite A, Franchi L. STAT3 tyrosine phosphorylation is critical for interleukin 1 beta and interleukin- 6 production in response to lipopolysaccharide and live bacteria. Mol Immunol 2009; 46:1867-1877.

44 Lee C, Lim HK, Sakong J, Lee YS, Kim JR, Baek SH. Janus kinase-signal transducer and activator of transcription mediates phosphatidic acid-induced interleukin (IL)-1beta and IL-6 production. Mol Pharmacol 2006; 69:1041-1047. 
45 Yu Z, Zhang W, Kone BC. Signal transducers and activators of transcription 3 (STAT3) inhibits transcription of the inducible nitric oxide synthase gene by interacting with nuclear factor kappaB. Biochem J 2002; 367:97-105.

46 Lee H, Herrmann A, Deng JH, et al. Persistently activated Stat3 maintains constitutive NF-kappaB activity in tumors. Cancer Cell 2009; 15:283-293.

47 Huang WL, Yeh HH, Lin CC, et al. Signal transducer and activator of transcription 3 activation up-regulates interleukin-6 autocrine production: a biochemical and genetic study of established cancer cell lines and clinical isolated human cancer cells. Mol Cancer 2010; 9:309.

48 Cai B, Li J, Wang J, et al. microRNA-124 regulates cardiomyocyte differentiation of bone marrow-derived mesenchymal stem cells via targeting STAT3 signaling. Stem Cells 2012; 30:17461755.

49 Hatziapostolou M, Polytarchou C, Aggelidou E, et al. An
HNF4 $\alpha$-miRNA inflammatory feedback circuit regulates hepatocellular oncogenesis. Cell 2011; 147:1233-1247.

50 Hou J, Wang P, Lin L, et al. MicroRNA-146a feedback inhibits RIG-I-dependent type I IFN production in macrophages by targeting TRAF6, IRAK1, and IRAK2. J Immunol 2009; 183:2150-2158.

51 Wang C, Chen T, Zhang J, et al. The E3 ubiquitin ligase Nrdp1 'preferentially' promotes TLR-mediated production of type 1 interferon. Nat Immunol 2009; 10:744-752.

(Supplementary information is linked to the online version of the paper on the Cell Research website.)

(c) (i) (3) $)$ This work is licensed under the Creative Commons Attribution-NonCommercial-No Derivative Works 3.0 Unported License. To view a copy of this license, visit http:// creativecommons.org/licenses/by-nc-nd/3.0 